\title{
EFFECT OF TEMPERATURE AND OXIDATION IN CUTTING ZONE ON WEAR OF CUTTING TOOLS WITH MULTILAYER COMPOSITE NANO-STRUCTURED COATINGS AT HIGH SPEED TURNING
}

\author{
M. Volosova ${ }^{1}$, A. Vereschaka ${ }^{1}$, A. Okunkova ${ }^{1}$, N. Sitnikov², \\ N. Andreev ${ }^{3}$, F. Milovich ${ }^{3}$, and J. Bublikov ${ }^{4}$ \\ ${ }^{1}$ Moscow State Technological University STANKIN, Moscow, Russia \\ ${ }^{2}$ National Research Nuclear University MEPhl (Moscow Engineering Physics Institute), Moscow, Russia \\ ${ }^{3}$ National University of Science and Technology "MISIS," Moscow, Russia \\ ${ }^{4}$ IKTI RAN, Vadkovsky per. 18-1A, Moscow, 127055, Russia \\ *Corresponding author; e-mail: dr.a.veres@yandex.ru
}

\begin{abstract}
The article discusses the ability of multilayer composite nano-structured coatings based on the $\mathrm{Cr}-\mathrm{CrN}$ $(\mathrm{Ti}, \mathrm{Cr}, \mathrm{Al}, \mathrm{Si}) \mathrm{N}$ system to resist wear factors activated with increasing temperature, such as diffusion and oxidation processes, as well as spinodal decomposition of the coating material. Investigators were carried out in turning C45 steel at the following cutting conditions: $f=0.2 \mathrm{~mm} / \mathrm{rev}, a_{p}=1.0 \mathrm{~mm}, v_{c}=300 \mathrm{~m} / \mathrm{min}$. SEM and TEM techniques were used to investigate changes in nano-structures of coatings, as well as diffusion and oxidation processes. Of particular interest was the study of a layer of nanometric thickness on the rake surface of the tool, between the adhered material being machined and the surface nanolayers of the coating. The content of oxygen, iron, and metals the coating was investigated. A lot significant difference was revealed in the content of elements in the layer investigated, depending on the location of the area studied around a crater on the rake face of the tool.
\end{abstract}

Keywords:

Multilayered nanostructured coatings; wear; metal cutting tools; nanolayer; diffusion processes; oxidation

\section{INTRODUCTION}

As is known, an increase in cutting speed is associated with a marked increase in temperature in the cutting zone. Thus, an increase in heat resistance of wear-resistant coatings is a significant resource for increasing the cutting speed and, consequently, the overall performance of cutting. Cutting tools with the $(\mathrm{Ti}, \mathrm{Cr}, \mathrm{Al}) \mathrm{N}$ coatings are widely used due to their high hardness and wear resistance, as well as considerably high thermal resistance of the above coatings [Chang 2009, Ezura 2008, Ichijo 2007, Zhang 2011, Jung 2013, Kuo 2017, Yamamoto 2003, Yamamoto 2005]. Moreover, the introduction of Si into the composition of the above coatings contributes to an additional increase in thermal resistance, crack resistance, and resistance to brittle fracture due to the formation of nanocomposite structures. It was found [Chang 2009] that when the total content of $\mathrm{Al}$ and $\mathrm{Si}$ in the (Ti,Cr,Al,Si)N coating was 60 at\%, a cubic structure of the $\mathrm{NaCl}$-type was formed, and with an increase in the content of $\mathrm{Al}$ and $\mathrm{Si}$, the cubic structure transformed into a hexagonal one. Meanwhile, the maximum hardness was shown by a coating with the cubic structure [Ezura 2008, Ichijo 2007, Zhang 2011, Jung 2013, Kuo 2017, Sobol' 2012, Metel 2011], and the coating stayed resistant to the oxidation until $1000^{\circ} \mathrm{C}$ [Yamamoto 2003, Yamamoto 2008]. Investigation into the resistance to thermal oxidation of the coating revealed the formation of a thin oxide layer with the high Si content between the main oxide layer and the coating [Yamamoto 2008, Fominski 2012]. Chang et al. [Chang 2009] considered the $\left(\mathrm{Cr}_{0.36} \mathrm{Al}_{0.57} \mathrm{Si}_{0.07}\right) \mathrm{N}$ and $\left(\mathrm{Cr}_{0.40} \mathrm{Ti}_{0.22} \mathrm{Al}_{0.36} \mathrm{Si}_{0.02}\right) \mathrm{N}$ coatings with nanocrystalline structures. When the coating was heated up to $900^{\circ} \mathrm{C}$, the oxide phases of $\mathrm{TiO}_{2}, \mathrm{Al}_{2} \mathrm{O}_{3}$, and $\mathrm{Cr}_{2} \mathrm{O}_{3}$ were formed on its surface. It was found that the protective oxide layer formed by oxides of $\mathrm{Al}_{2} \mathrm{O}_{3}$ and $\mathrm{Cr}_{2} \mathrm{O}_{3}$ prevented the diffusion of oxygen into the coating structure. Meanwhile, the oxidation resistance was improved with an increase in the content of $(\mathrm{Al}, \mathrm{Si}) \mathrm{N}$. Zhang et al. [Zhang 2013] studied the nanolayer $(\mathrm{Cr}, \mathrm{Al}, \mathrm{Si}) \mathrm{N}$ coating. An important feature of the coating is the very low friction coefficient $(0.1-0.2)$. The authors explain the above figures by the fact that the coating had a very high cohesive energy of interfacial relationships, while the epitaxial growth created a field of alternating stresses that restrained the movement of dislocations and increased the hardness of the coating. Nguyen et al. [Nguyen 2009] investigated the thermal oxidation of the $(\mathrm{Ti}, \mathrm{Al}, \mathrm{Cr}, \mathrm{Si}) \mathrm{N}$ coating at the 
temperature of $1000^{\circ} \mathrm{C}$. It was found that under those conditions, the oxide phases of $\mathrm{Cr}_{2} \mathrm{O}_{3}, \alpha-\mathrm{Al}_{2} \mathrm{O}_{3}, \mathrm{SiO}_{2}$, as well as $\mathrm{TiO}_{2}$ (rutile) were formed on the surface of the coating. In that case, $\mathrm{TiO}_{2}$ was registered predominantly in the outer part of the oxide layer, while $\mathrm{Cr}_{2} \mathrm{O}_{3}$ and $\alpha-\mathrm{Al}_{2} \mathrm{O}_{3}$ in its inner part. The content of the $\mathrm{SiO}_{2}$ phase in the oxide layer was very low due to its low mobility.

Thus, it can be argued that the addition of $\mathrm{Si}$ in the ( $\mathrm{Ti}, \mathrm{Cr}, \mathrm{Al}) \mathrm{N}$ coating contributes to the formation of nanograin structure, increase in hardness, heat resistance, and resistance to thermal oxidation. The formation of nanolayer structure of the coating contributes not only to an increase in its hardness, heat resistance, and resistance to thermal oxidation due to the formation of alternating interlayer interfaces that prevent the oxygen diffusion, but such a formation also provides a rational combination of high hardness with high strength and toughness.

The above features of the coatings based on the ( $\mathrm{Ti}, \mathrm{Al}, \mathrm{Cr}, \mathrm{Si}) \mathrm{N}$ system contribute to an assumption about the prospects of using it as a coating for a cutting tool.

\section{MATERIALS AND METHODS}

The Filtered Cathodic Vacuum Arc Deposition (FCVAD) [Vereschaka 2013, Vereschaka 2016] technology was implemented using VIT-2 installation (IKTI RAN - MSTU STANKIN, Russia). VIT-2 was equipped with a system for filtration of droplets formed at the evaporation of refractory metals such as $\mathrm{Al}, \mathrm{Ti}, \mathrm{Cr}$; a mechanism for suppression of micro arcs; a dynamic gas mixing system and a generator of high energy ions.

Samples for metallographic studies were prepared on equipment for metallographic sections manufactured by BUEHLER Company (Isomet 1000 precision cutting machine, Simplimet 1000 automatic hydraulic mounting press, and EcoMet 250 + AutoMet 250 automatic grinder and polisher machine)

An analysis of the microstructure and nanostructure of the specimens was studied using JEM 2100 (JEOL, Japan) high-resolution transmission electron microscope (TEM) with an accelerating voltage of $200 \mathrm{kV}$. The chemical composition of the samples was studied using an energydispersive X-ray spectroscopy (EDXS; INCA Energy; Oxford Instruments, England). Sample preparation for the TEM was carried out using a focused ion beam (FEI Strata FIB 201) with an accelerating voltage of $30 \mathrm{kV}$.

The tests to study the tool life and wear dynamics for the carbide inserts SNUN ISO 1832:2012 ( $\mathrm{H} 10$ grade $-\mathrm{WC}+$ $5 \% \mathrm{TiC}+6 \% \mathrm{Co}$; KZTS, Russia) were conducted at a CU 500 MRD lathe manufactured by Sliven Company with the ZMM CU500MRD variable speed drive in turning workpieces made of AISI C45 steel $(400 \mathrm{~mm}$ long and an initial diameter of $250 \mathrm{~mm}$ ). No coolants or lubricants were used in the cutting process. The parameters of the carbide inserts in a cutting tool holder were as follows: $\gamma=-7^{\circ}, \alpha=$ $7^{\circ}, \lambda=0^{\circ}$, and $r=0.4 \mathrm{~mm}$. In addition, the cutting conditions were as follows: $f=0.25 \mathrm{~mm} / \mathrm{rev}, a_{p}=1.0 \mathrm{~mm}, v_{c}=300$ $\mathrm{m} / \mathrm{min}$. The flank wear land $\mathrm{VB}_{\max }=0.45 \mathrm{~mm}$ was assumed as a wear criterion. Each test was repeated at least five times; when determining the average wear values, the minimum and maximum values were discarded.

\section{RESULTS AND DISCUSSION}

The study was focused on the carbide cutting tool with the multilayer composite nano-structured $\mathrm{Cr}$-CrN-(Ti,Cr,Al,Si)N coating which showed its good performance properties in previous studies [Vereschaka 2018, Vereschaka 2019].
The coating structure (Fig.1) included the adhesive Cr layer with the thickness of about $20 \mathrm{~nm}$, the transition CrN layer with the thickness of $300 \mathrm{~nm}$, and the wear-resistant ( $\mathrm{Ti}, \mathrm{Cr}, \mathrm{Al}, \mathrm{Si}) \mathrm{N}$ layer with the thickness of $2.4 \mu \mathrm{m}$, which had a nanolayer structure [Vereschaka 2018, Vereschaka 2019, Vereschaka 2016].

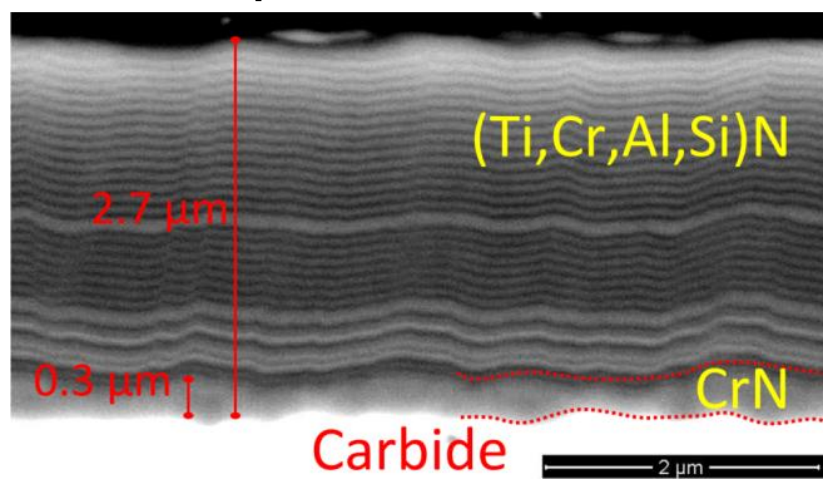

Fig. 1. Architecture of the Cr-CrN-(Ti,Cr,Al,Si)N coating (SEM).

With a larger magnification (Fig. 2), it can be seen that in turn, each nanolayer consists of several subnanolayers with the thicknesses of 2-7 $\mathrm{nm}$. The formation of these subnanolayers can be associated with the planetary rotation of the tool set during the coating deposition.

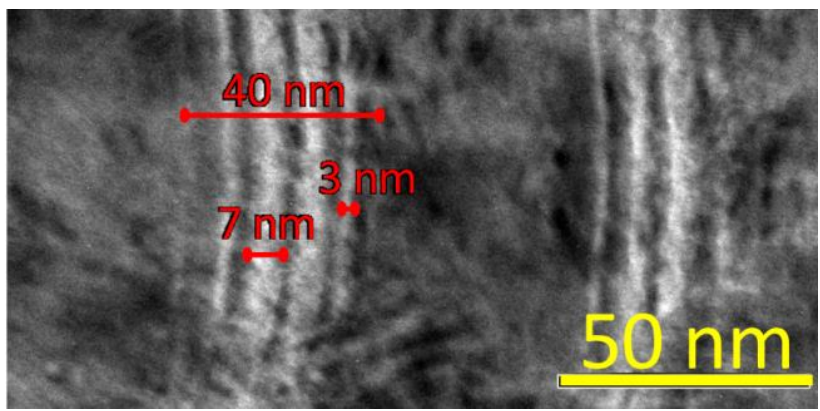

Fig. 2. Nano-structure of the wear-resistant layer of the coating.

Figure 3 presents the results of the investigation into the cutting properties of the tool with the coating under study in turning C45 steel. The tool with this coating showed a higher tool life period both in comparison with the uncoated tool and with the tool with the commercial monolithic (Ti,Al)N coating.

The dynamics of tool wear with the test coating is shown in Fig. 4a.

To investigate the diffusion and oxidation processes in the cutting zone, as well as the influence of high temperatures on the chemical composition of the coating, the study was focused on the area of a bridge between the crater and the main cutting edge (Fig. 4b). This area is usually associated with the formation of an adherent and a stagnant zone that protect the bridge from wear and destruction. 


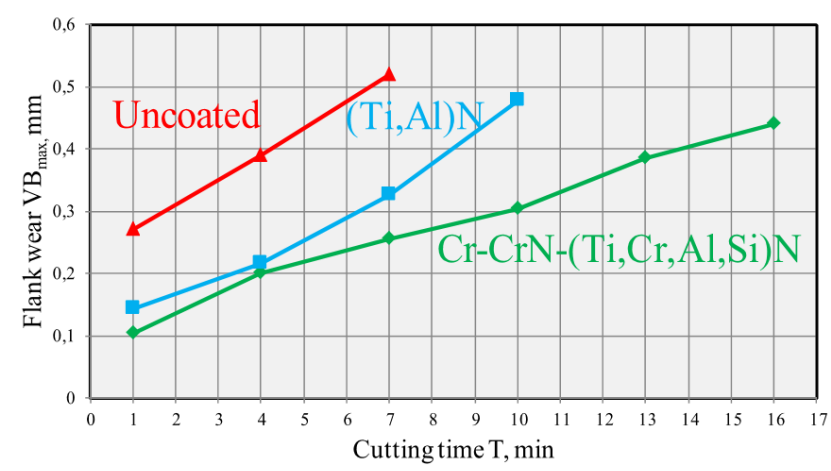

Fig. 3. Relationship between the flank wear and the cutting time in turning a workpiece made of C45 steel.
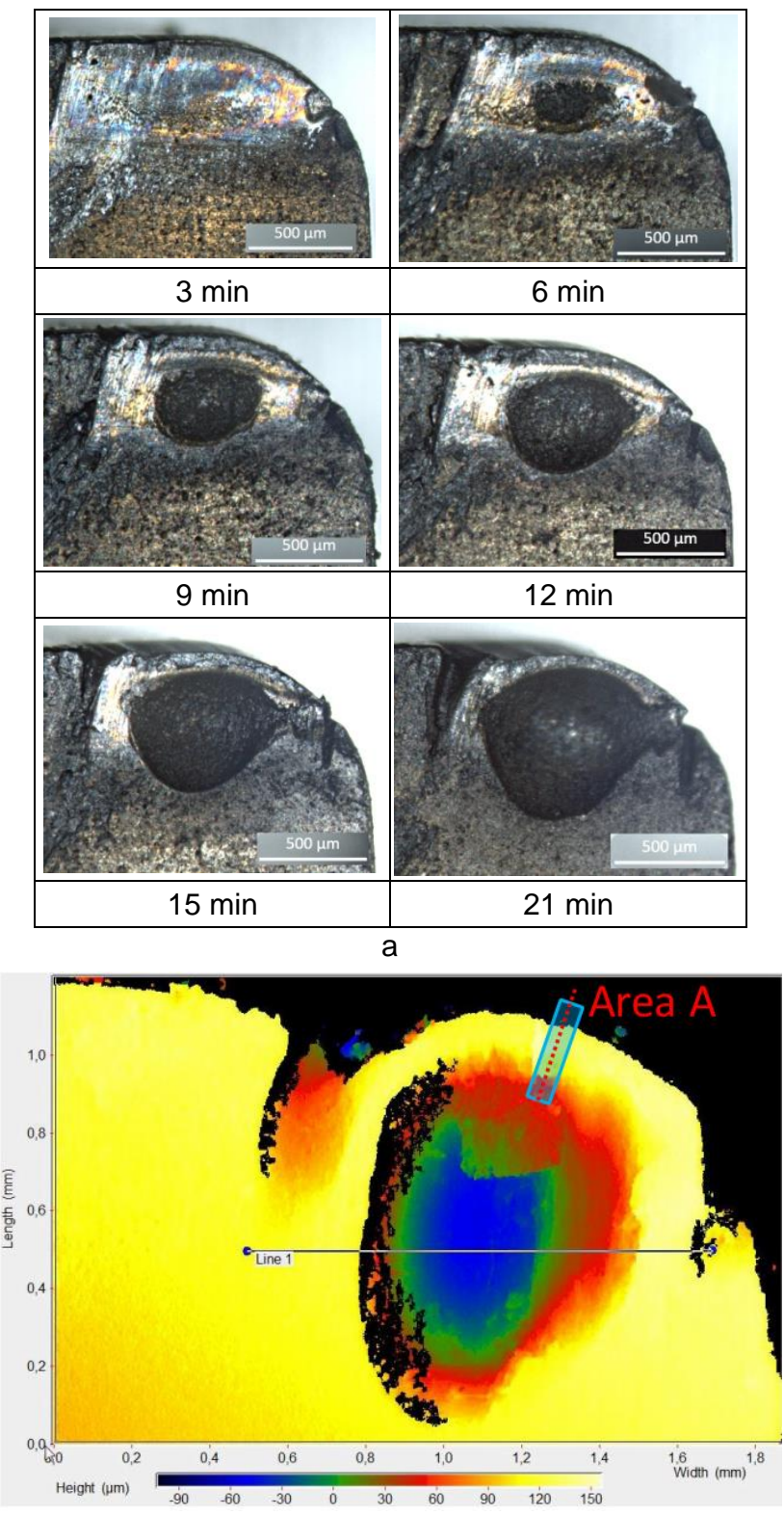

b

Fig. 4. The tool rake wear (a) and 3-D scan of the wear area on the carbide insert with the coating (b) after 21 minutes of cutting.

Figure 5 shows cross sectional area (a) and the nanolayer structure of the wear-resistant layer of the coating (b). The adherent of the material being machined, as well as the presence of a layer of the spinodal decomposition of the coating, referred to as the coating destruction layer (CDL). The thickness of the CDL in the area under study is about $700 \mathrm{~nm}$. There is a clear boundary between the destruction of the nanolayer structure of the coating and the transition to the CDL, and this fact can be considered as an indirect proof of the influence of the internanolayer interfaces on the inhibition of the development of the CDL. In Fig. 5c, it is possible to notice partial detachment of the adherent of the material being machined from the coating.

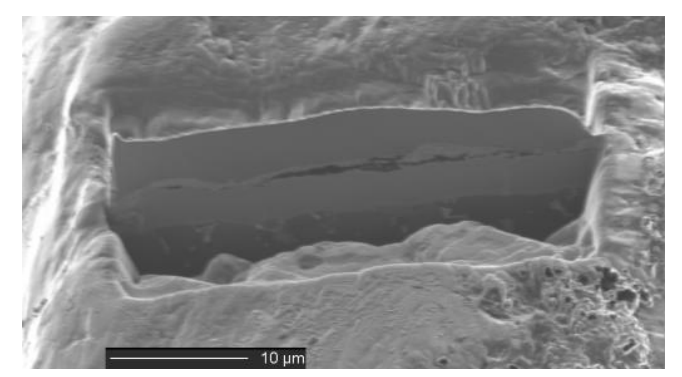

a

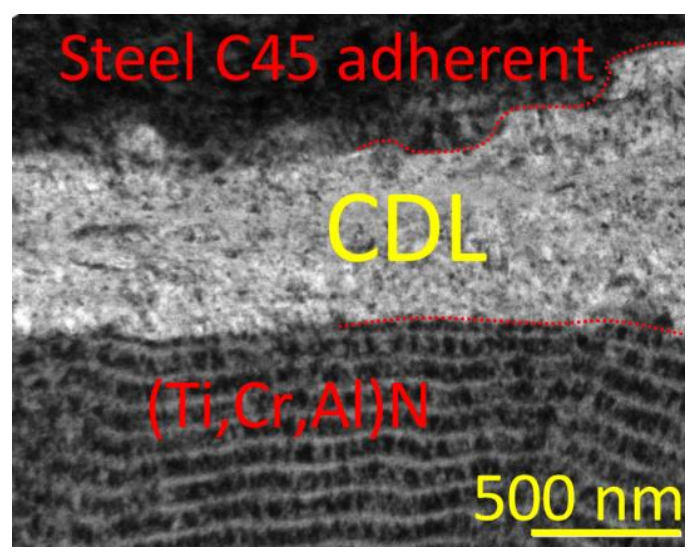

b

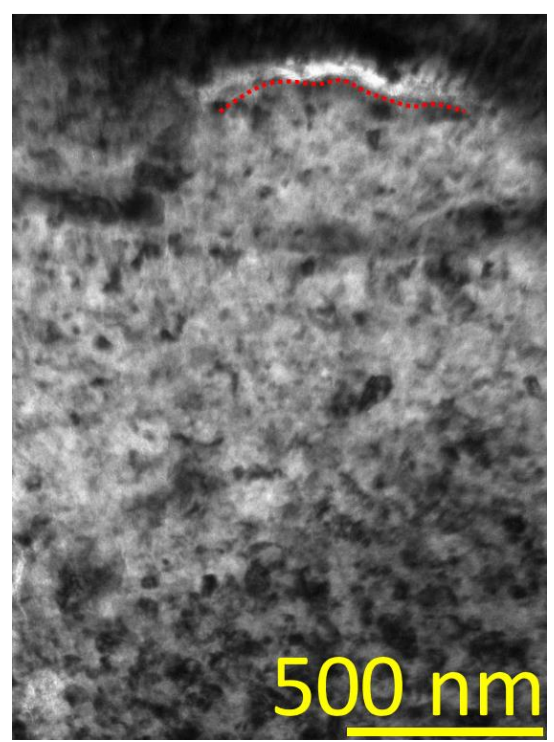

C

Fig. 5. Cross-section of the coating (a), nanolayer structure of the wear-resistant layer of the coating (b) partial detachment of the adherent of the material being machined from the coating(c).

Area A (Fig. 6) can be selected in the area under study to examine the chemical analysis of the coating destruction layer. The following distribution of elements in the CDL is typical for the area under study (Fig. 6). The low oxygen 
content in the composition of the above layer can be explained by the obstructed access of oxygen to the area in connection with the presence of the inhibited layer. It is possible to note the high content of $\mathrm{Al}$ with the low content of $\mathrm{Ti}$ and the very low content of $\mathrm{Cr}$. This fact can be associated with the process of separation of $\mathrm{Al}$ from the solid solution of $(\mathrm{Ti}, \mathrm{Cr}, \mathrm{Al}) \mathrm{N}$ and the formation of the wurtzite AIN phase at high temperatures, as well as with the process of the interface-directed spinodal decomposition, during which atoms of $\mathrm{Al}$ move to the nearest interface and accumulate in it [Povstugar 2013]. Meanwhile, the coating nanolayers adjacent to the coating destruction layer are characterized by a lower content of $\mathrm{Al}$ and higher contents of $\mathrm{Ti}$ and $\mathrm{Cr}$. There is insignificant diffusion of Fe from the material being machined in the coating destruction layer in the area under study.

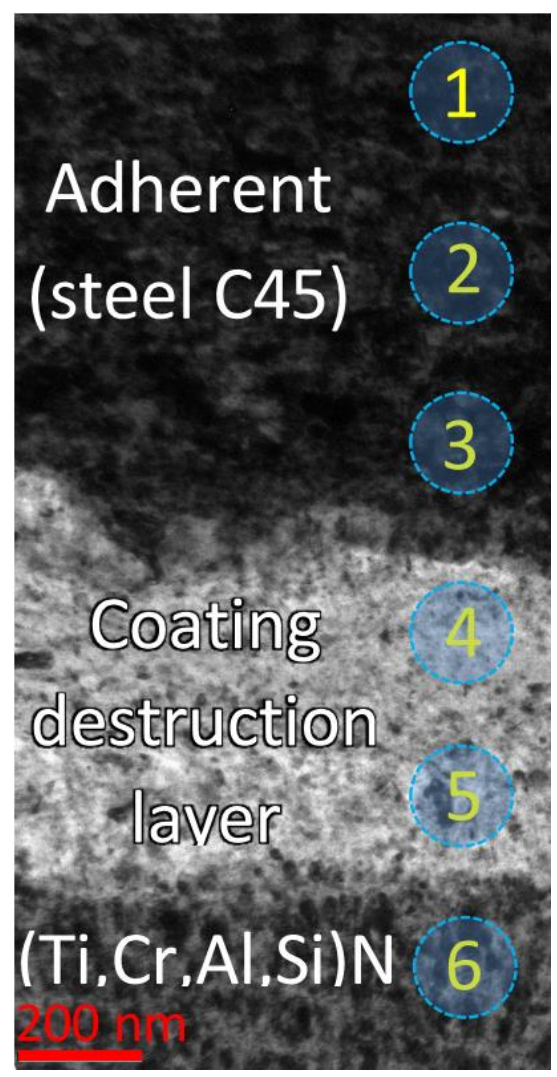

a

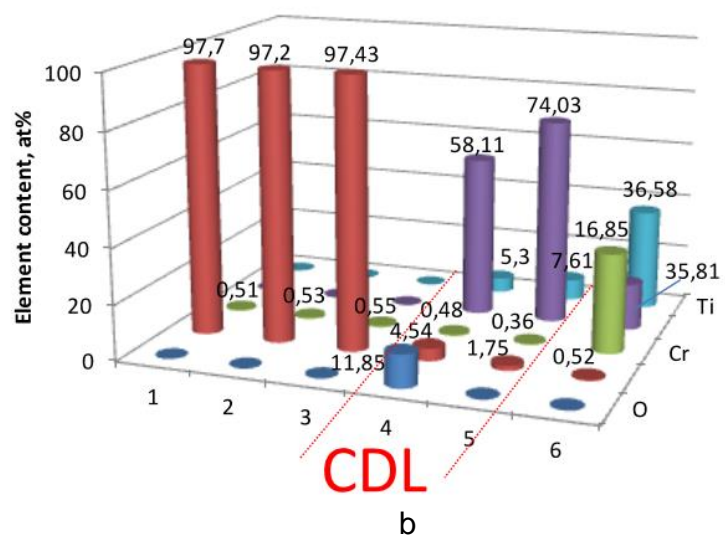

@ 0

Ee

$=\mathrm{Cr}$

Al $\square \mathrm{Ti}$

Fig. 6. Cross-cut of the coating (a) and content of chemical elements (b) in area $A$.

While considering the boundary area of the CDL (dashed line in Fig. 7), it is possible to notice a fairly clear boundary of the nanolayer structure of the coating, as well as rather large $(50-200 \mathrm{~nm})$ crystals which formed the CDL. In the very structure of the CDL, it is possible to note traces of the nanolayer structure conserved fragmentally.

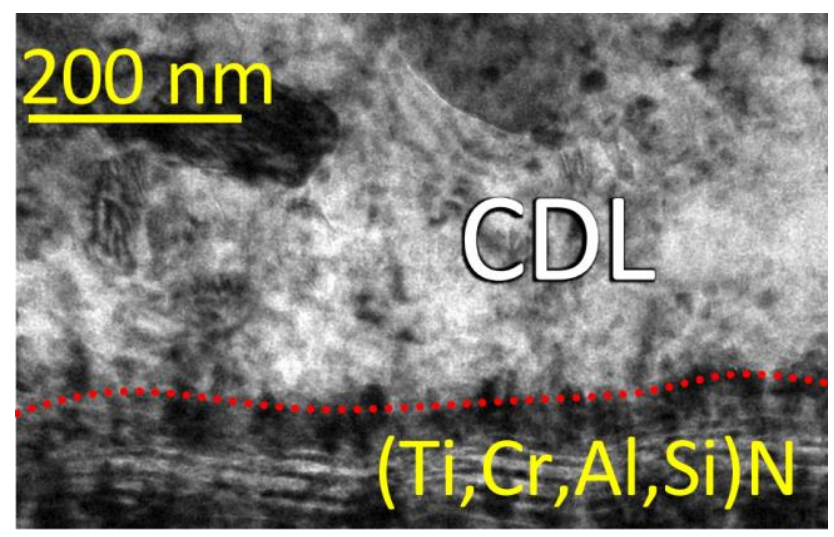

Fig. 7. Boundary of the decomposition of the coating nanostructure in the area under study.

\section{CONCLUSIONS}

The studies of boundaries of crater wear on the carbide tool with the $\mathrm{Cr}-\mathrm{CrN}-(\mathrm{Ti}, \mathrm{Cr}, \mathrm{Al}, \mathrm{Si}) \mathrm{N}$ coating revealed a layer with a lost nano-structure, referred to as the coating destruction layer (CDL). The studies also found out the thickness of the layer which reached about $700 \mathrm{~nm}$.

Since cutting occurs at a sufficiently high cutting speed $\left(v_{c}\right.$ $=300 \mathrm{~m} / \mathrm{min}$ ), oxidation processes in combination with temperature effects have a significant impact on the wear pattern. The result of this impact is the formation of an extensive crater wear on the rake surface.

The coating is formed by simultaneous exposure to high temperatures, diffusion and oxidation processes, as well as wear processes.

The studies found that the area (CDL) is quite clearly limited by the boundaries of the nanolayer, and this fact suggests that the interfaces between nanolayers restrain the development of the coating destruction layer.

\section{ACKNOWLEDGMENTS}

This work was financially supported by the Ministry of Education and Science of Russian Federation in the framework of the state task No. 9.7889.2017/8.9.

The work is carried out on the equipment of the Center of collective use of MSTU "STANKIN".

\section{REFERENCES}

[Chang 2009]. Chang, Y.-Y., Hsiao, C.-Y. High temperature oxidation resistance of multicomponent $\mathrm{Cr}-\mathrm{Ti}-\mathrm{Al}-\mathrm{Si}-\mathrm{N}$ coatings. Surface \& Coatings Technology, 2009, Vol. 204, pp 992-996

[Ezura 2008] Ezura, H., et al. Micro-hardness, microstructures and thermal stability of $(\mathrm{Ti}, \mathrm{Cr}, \mathrm{Al}, \mathrm{Si}) \mathrm{N}$ films deposited by cathodic arc method. Vacuum, 2008, Vol. 82, pp 476-481

[Ichijo 2007] Ichijo, K., Hasegawa, H., Suzuki, T. Microstructures of $(\mathrm{Ti}, \mathrm{Cr}, \mathrm{Al}, \mathrm{Si}) \mathrm{N}$ films synthesized by cathodic arc method. Surface \& Coatings Technology, 2007, Vol. 201, pp 5477-5480 
[Jung 2013]. Jung, D.H., Moon, K.I., Shin, S.Y., Lee, C.S Influence of ternary elements $(X=\mathrm{Si}, \mathrm{B}, \mathrm{Cr})$ on TiAIN coating deposited by magnetron sputtering process with single alloying targets. Thin Solid Films, 2013, Vol. 546, pp 242245

[Kuo 2017] Kuo, Y.-C., Wang, C.-J., Lee, J.-W. The microstructure and mechanical properties evaluation of CrTiAISiN coatings: Effects of silicon content. Thin Solid Films, 2017, Vol. 638, pp 220-229.

[Sobol'] Sobol', O. V., Andreev, A. A., Grigoriev, S. N. Vacuum-arc multilayer nanostructured TiN/Ti coatings: structure, stress state, properties. Metal Science And Heat Treatment, 2012 Vol. 54 (1-2), pp. 28-33

[Metel] Metel, A., Grigoriev, S., Melnik, Y. Cutting Tools Nitriding in Plasma Produced by a Fast Neutral Molecule Beam. Japanese Journal Of Applied Physics, 2011 Vol. 50(8) 08JG04

[Fominski] Fominski, V. Yu., Grigoriev, S. N., Celis, J. P. Structure and mechanical properties of W-Se-C/diamondlike carbon and W-Se/diamond-like carbon bi-layer coatings prepared by pulsed laser deposition. Thin Solid Films, 2012 Vol. 520(21) pp.6476-6483

[Fominski] Fominski, V. Yu., Grigoriev, S. N., Gnedovets, A. G. Pulsed laser deposition of composite Mo-Se-Ni-C coatings using standard and shadow mask configuration. Surface \& Coatings Technology, 2012 Vol. 206(24) pp. 5046-5054

[Nguyen 2009]. Nguyen, T.D., Kim, S.K., Lee, D.B. Hightemperature oxidation of nano-multilayered TiAICrSiN thin films in air. Surface \& Coatings Technology, 2009, Vol. 204, pp 697-704

[Povstugar 2013] Povstugar, I., et al. Interface-directed spinodal decomposition in TiAIN/CrN multilayer hard coatings studied by atom probe tomography. Acta Materialia, 2013, Vol. 61, pp 7534-7542

[Vereschaka 2013] Vereschaka, A.A., et al. Development and research of environmentally friendly dry technological machining system with compensation of physical function of cutting fluids. Procedia CIRP, 2013 Vol. 7, pp 311-316

[Vereschaka 2016] Vereschaka, A.S., et al. Control of structure and properties of nanostructured multilayer composite coatings applied to cutting tools as a way to improve efficiency of technological cutting operations. Journal of Nano Research, 2016, Vol. 37, pp 51-57

[Vereschaka 2018] Vereschaka, A., et al. Effect of adhesion and tribological properties of modified composite nano- structured multi-layer nitride coatings on WC-Co tools life. Tribology International, 2018, Vol. 128, pp 313-327

[Vereschaka 2019] Vereschaka, A., et al. Investigation of wear dynamics for cutting tools with multilayer composite nanostructured coatings in turning constructional steel. Wear, 2019, Vol. 420-421, pp 17-37

[Vereschaka 2018] Vereschaka, A., et al. Investigation of wear and diffusion processes on rake faces of carbide inserts with $\mathrm{Ti}-\mathrm{TiN}-(\mathrm{Ti}, \mathrm{Al}, \mathrm{Si}) \mathrm{N}$ composite nanostructured coating. Wear, 2018, Vol. 416-417, pp 72-80.

[Vereschaka 2019] Vereschaka A., et al. Effect of adhesion and the wear-resistant layer thickness ratio on mechanical and performance properties of $\mathrm{ZrN}-(\mathrm{Zr}, \mathrm{Al}, \mathrm{Si}) \mathrm{N}$ coatings. Surface \& Coatings Technology, 2019, Vol. 357, pp 218234

[Vereschaka 2016] Vereschaka, A.A., et al, Development and research of nanostructured multilayer composite coatings for tungsten-free carbides with extended area of technological applications. Int. J. Adv. Manuf. Technol., 2016, Vol. 87, pp 3449-3457.

[Yamamoto 2003] Yamamoto, K., Sato, T., Takahara, K., Hanaguri, K. Properties of $(\mathrm{Ti}, \mathrm{Cr}, \mathrm{Al}) \mathrm{N}$ coatings with high Al content deposited by new plasma enhanced arc-cathode. Surface and Coatings Technology, 2003, Vol. 174-175, pp 620-626

[Yamamoto 2005]. Yamamoto, T., Hasegawa, H., Suzuki, T., Yamamoto, K. Effects of thermal annealing on phase transformation and microhardness of (TixCryAlz) N films. Surface \& Coatings Technology, 2005, Vol. 200, pp 321325

[Yamamoto 2008]. Yamamoto, K., Kujime, S., FoxRabinovich, G. Effect of alloying element (Si,Y) on properties of AIP deposited $(\mathrm{Ti}, \mathrm{Cr}, \mathrm{Al}) \mathrm{N}$ coating. Surface \& Coatings Technology, 2008, Vol. 203, pp 579-583

[Zhang 2013]. Zhang, S., Wang, L., Wang, Q., Li, M. A superhard CrAISiN superlattice coating deposited by multiarc ion plating: I. Microstructure and mechanical properties. Surface \& Coatings Technology, 2013. Vol. 214, pp 160167

[Zhang 2011]. Zhang, J., Lu, H., Cui, G., Jing, Z. Chuang Wang. Effects of bias voltage on the microstructure and mechanical properties of $(\mathrm{Ti}, \mathrm{Al}, \mathrm{Cr}) \mathrm{N}$ hard films with $\mathrm{N}$ gradient distributions. Thin Solid Films, 2011, Vol. 519, pp 4818-4823 